\title{
AN IMPROVED ONE-POT SYNTHESIS OF $N$-(2,3-DIHYDROBENZO[1,4]DIOXIN-2-CARBONYL)PIPERAZINE - USEFUL INTERMEDIATE FOR ANTI-HYPERTENSIVE DRUG - DOXAZOSIN
}

\author{
Chakka Ramesh", Reguri Buchi Reddy and Ghanta Mahesh Reddy ${ }^{*}$ \\ "Department of Research and Development; Dr. Reddys Laboratories Limited,7-1-27, Ameerpet, \\ Hyderabad - 500 016, Andhra Pradesh, India. \\ maheshrg@drreddys.com

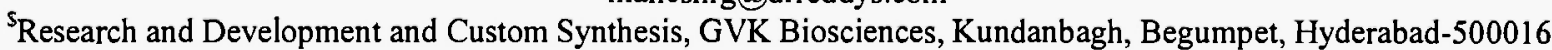 \\ DRL-IPDO-IPM Communication \# 000017
}

\begin{abstract}
An improved process for the preparation of $N$-(2,3-dihydrobenzo[1,4]dioxin-2carbonyl)piperazine 2 and its hydrochloride from ethyl-2,3-dihydro-1,4-benzodioxin-2-carboxylate 3 and piperazine in a single step has been described. The compound 2 is an important intermediate in the preparation of anti-hypertensive agent, Doxazosin.
\end{abstract}

\section{Introduction}

$\mathrm{N}$-Acylalkylenediamines ${ }^{(1)}$ are used to react with 4-amino-2-chloro-6,7-dimethoxy quinazolines 4 to give a variety of anti-hypertensive agents. ${ }^{(2)}$ For example Doxazosin mesylate $\mathbf{1}$ is an anti-hypertensive drug contains $\mathrm{N}$-acylalkylenediamine moiety.<smiles>COc1cc2nc(N3CCN(C(=O)C4COc5ccccc5O4)CC3)nc(N)c2cc1OC</smiles>

Doxazosin mesylate $\mathbf{1}$ is indicated for the treatment of the urinary outflow obstruction and obstructive and irrigative symptoms associated with benign prostate hyperplasia (BPH), obstructive symptoms (hesitation, intermittency, dribbling, weak urinary stream, incomplete emptying of the bladder) and irritative symptoms (nocturia, daytime frequency, urgency, burning). Doxazosin mesylate 1 is also indicated for the treatment of hypertension. It shows a great structural similarity to the older representatives of this class, Prazosin hydrochloride and Terazosin hydrochloride, whereas the two latter active substances are used primarily in the treatment of high blood pressure. In the case of compound $\mathbf{1}$, there is an additional indication, namely, the treatment of BPH. Unlike Prazosin and Terazosin, 1 is used therapeutically not as hydrochloride but as the mesylate, that is, as a salt of methane sulfonic acid.

The synthesis leads to an improved process for the preparation of $N$-(2,3-dihydro-1,4-benzodioxin-2-ylcarbonyl)piperazine 2 and its hydrochloride from ethyl-2,3-dihydro-1,4-benzodioxin-2-carboxylate 3 in a single step. The yields are comparatively higher and consistent. The compound $N$-(2,3-dihydro-1.4benzodioxin-2-yl carbonyl) piperazine $\mathbf{2}$ is an important intermediate in the preparation of antihypertensive agent, Doxazosin. 


\section{Results and Discussions}

A variety of methods for the synthesis of 1 have been reported. Out of the available methods, the initial preparation involves the condensation of 4-amino-2-chloro-6,7-dimethoxyquinazoline 4 with $\mathrm{N}$-(2,3dihydro-1.4-benzodioxin-2-yl carbonyl) piperazine 2 to produce Doxazosin $1^{(3)}$

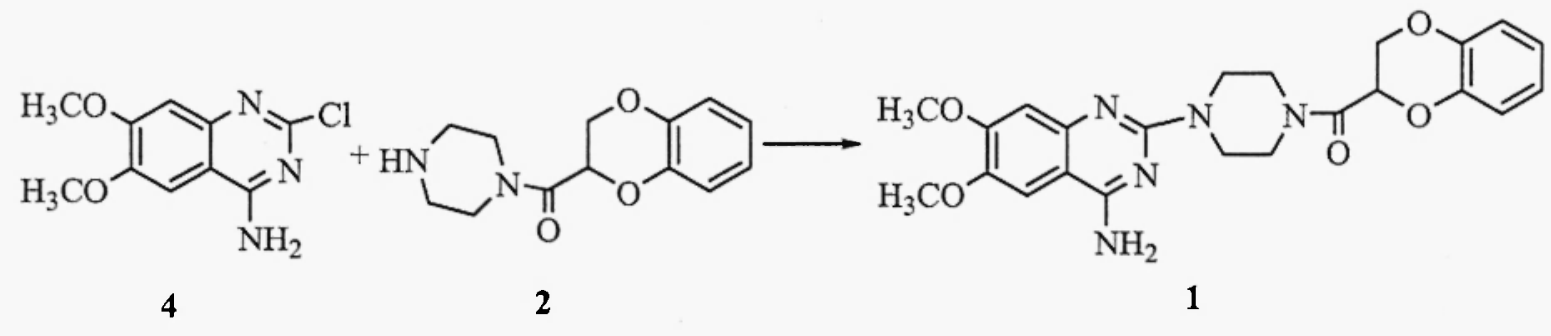

Scheme-1

The compound $\mathbf{2}$ is an important intermediate, which is involved in the above synthetic process for the preparation of 1 . The preparation of this intermediate has been reported in literature through different routes.

The intermediate 2 was prepared from catechol through a series of reactions, involving the reaction of catechol with esters of 2,3-dibromopropionic acid to produce corresponding benzodioxin-2-carboxylic esters 3, which upon hydrolysis with ethanolic sodium hydroxide or aqueous hydrobromic acid produces corresponding acid. The acid is converted into its acid chloride with thionyl chloride in benzene which is then treated with piperazine to produce compound $2 .^{(1 \mathrm{a}, 3 \mathrm{a}-\mathrm{b})}$ The intermediate 2 can also be prepared by the direct reaction of esters of benzodioxin-2-carboxylic acid with piperazine without using solvents under nitrogen atomosphere at certain temperatures. According to this reference no amidation occurs on treatment of ester with piperazine in refluxing THF, $\mathrm{CH}_{3} \mathrm{CN}, \mathrm{DMF}$, or benzene for several hours in the presence of sodium methoxide. ${ }^{(4)}$ Swamy et al., ${ }^{(5)}$ identifies the presence of bis- $N$ - $(2,3-$ dihydro- $1,4-$ benzodioxin-2-yl carbonyl)piperazine in the process provided by the above reference and their process involves the removal of bis-impurity by the acid-base treatment.

Further, 2 is also known to prepare by the reaction of esters of benzodioxin-2-carboxylic acid with piperazine in aromatic hydrocarbon solvents such as benzene, toluene, xylene. ${ }^{(6)}$ Other process disclosed in the literature involves the use of a reaction of benzodioxin-2-carboxylic acid with piperazine in the presence of $N$-methyl morpholine or 2-chloro-4, 6-dimethoxy-1,3,5-triazine in chloroform. ${ }^{(7)}$

The reported methods for the preparation of $\mathbf{2}$ have some disadvantages like involves many steps, employ hazardous chemicals like $\mathrm{HBr}$, thionyl chloride, THF, benzene which would have adverse impact on the health and environment, formation of bis- $\mathrm{N}$-(2,3-dihydro-1,4-benzodioxin-2-yl carbonyl)piperazine and tedious workup which make the process uneconomical on a commercial scale. Further, the neat reactions are not viable on commercial level. The above said circumstances and also the increasing the demand for $\mathbf{2}$, inspired us to develop an improved process for the preparation of $\mathbf{2}$ and its hydrochloride salt in a single step from 3 involving simple and non-hazardous chemicals and hence this improved process is environmental friendly.

Accordingly, the present process for the preparation of $\mathbf{2}$ and its hydrochloride salt from $\mathbf{3}$ in a single step which by the condensation with piperazine in aliphatic lower alcohols at reflux temperatures for 15-35 hrs followed by acid-base treatment to reduce unwanted impurity, bis- $N$-(2,3-dihydro-1,4-benzodioxin-2-yl carbonyl)piperazine and isolating the compound as its free base or its hydrochloride salt. 
<smiles>CC#CN1CCN(C(=O)C2COc3ccccc3O2)CC1</smiles>

Scheme-2

The solvents, which can be employed for the preparation of $\mathbf{2}$ with $\mathbf{3}$ and piperazine, alcohols such as methanol, ethanol, isopropanol. A combination of any two of these solvents can also be employed during condensation. Water immiscible organic solvents such as chloroform, dichloromethane or ethyl acetate can be used for the extraction of 2 from alkaline aqueous layer. The combined organic extracts are dried over anhydrous sodium sulphate/magnesium sulphate. The solvent is removed by distillation under vacuum to obtain 2 . The hydrochloride salt of 2 is obtained by passing hydrogen chloride gas into the organic extract, which precipitates out. The isolation of $\mathbf{2}$ is straight forward, requiring simple filtration, and all reaction by-products are easily removed from the reaction. All the solvents can be recovered and recycled any number of times without effecting the quality and yield of $\mathbf{2}$ and its hydrochloride salt. Therefore, the wastage is minimized to a great extent.

\section{Experimental Section}

The ${ }^{1} \mathrm{H}$ and ${ }^{13} \mathrm{C}$ NMR spectra were recorded at $400 \mathrm{MHz}$ and $50 \mathrm{MHz}$ respectively on a Gemini FT NMR Spectrometer, the chemical shifts were reported on $\delta$ ppm relative to TMS. The IR spectra were recorded in the solid state as $\mathrm{KBr}$ dispersion using Perkin Elmer FT-IR Spectrophotometer. The mass spectra were recorded on Shimadzu LCMS-QP 8000 LC-MS and AB-4000 Q-trap LC-MS/MS. Ester 3 was prepared according to reported procedure. ${ }^{(\text {la })}$

\section{General Procedure}

Preparation of $\mathrm{N}$-(2,3-dihydro-1,4-benzodioxin-2-yl carbonyl) piperazine 2:

A solution of ethyl-2,3-dihydro-1,4-benzodioan-2-carboxylate 3 was added slowly to a stirred mixture of piperazine in alcohol (s) at reflux. The reaction mass was maintained at reflux for 15-35 hrs and the solvent was distilled off from the reaction mass. Water was added to the residue and extracted with appropriate immiscible solvents. The organic solvent extracts were washed with water, dried and distilled to dryness to give $\mathrm{N}$-(2,3-dihydro-1,4-benzodioxin-2-yl carbonyl) piperazine 2 . MS m/z $248\left(\mathrm{M}^{+}\right) ;{ }^{1} \mathrm{H}$ $\operatorname{NMR}\left(\mathrm{CDCl}_{3}\right): 2.26(\mathrm{~s}, 1 \mathrm{H}, \mathrm{NH}), 2.77-2.89(\mathrm{~m}, 2 \mathrm{H}), 2.93-2.99(\mathrm{~m}, 2 \mathrm{H}), 3.52-3.57(\mathrm{~m}, 2 \mathrm{H}), 3.74-3.82(\mathrm{~m}$, $2 \mathrm{H}$ ), 4.33 (dd, $J=11.9,8.2 \mathrm{~Hz}, 1 \mathrm{H}), 4.56$ (dd, $J=11.9,2.5 \mathrm{~Hz}, 1 \mathrm{H}$ ), 4.89 (dd, $J=8.2,2.5 \mathrm{~Hz}, 1 \mathrm{H}$ ), 6.90$6.70(\mathrm{~m}, 4 \mathrm{H}) ;{ }^{13} \mathrm{C} \mathrm{NMR}\left(\mathrm{CDCl}_{3}\right): 42.9,45.6,46.2,46.9,65.0,70.3,116.9,117.2,121.1,122.0,143.0$, $143.5,165.1$; IR $(\mathrm{KBr}): 3427,1651 \mathrm{~cm}^{-1}$.

Table-1 : Physical data

\begin{tabular}{|c|c|c|c|c|c|}
\hline $\begin{array}{c}\text { Compound 3 } \\
(\mathbf{g})\end{array}$ & $\begin{array}{c}\text { Piperazine } \\
(\mathbf{g})\end{array}$ & Solvent & $\begin{array}{c}\text { Volume of solvent } \\
(\mathbf{m L})\end{array}$ & $\begin{array}{c}\text { Yield } \\
(\mathbf{g})\end{array}$ & $\begin{array}{c}\text { Yield } \\
(\mathbf{\%})\end{array}$ \\
\hline 50 & 62 & Isopropanol & 250 & 33 & 55 \\
\hline 50 & 62 & $\begin{array}{c}\text { Isopropanol }+ \\
\text { Methanol }\end{array}$ & $180+60$ & 43.6 & 73.13 \\
\hline 50 & 62 & $\begin{array}{c}\text { Isopropanol }+ \\
\text { Methanol }\end{array}$ & $180+60$ & 37 & 62 \\
\hline 41.6 & 51.6 & Methanol & 200 & 28.2 & 56.8 \\
\hline 41.6 & 51.6 & Ethanol & 200 & 30.3 & 61.1 \\
\hline
\end{tabular}




\section{Preparation of $N$-(2,3-dihydro-1,4-benzodioxin-2-yl carbonyl) piperazine hydrochloride} (hydrochloride salt of 2):

A solution of ethyl-2,3-dihydro-1,4-benzodioan-2-carboxylate 3 was added slowly to a piperazine in alcohol(s) at reflux. The reaction mass was maintained at reflux for 15-35 hrs and the solvent was distilled off from the reaction mass. Water was added to the residue and extracted with appropriate immiscible solvents. The organic solvent extracts were washed with water and $\mathrm{HCl}$ gas was passed till the $\mathrm{pH}$ of the reaction mass attains to 2 and maintained at the same $\mathrm{pH}$ for $15-30 \mathrm{~min}$. and filtered to isolate the hydrochloride salt of $N$-(2,3-dihydro-1,4-benzodioxin-2-yl carbonyl) piperazine 2 .

Table-2 : Physical data

\begin{tabular}{|c|c|c|c|c|c|}
\hline $\begin{array}{c}\text { Compound 3 } \\
(\mathrm{g})\end{array}$ & $\begin{array}{c}\text { Piperazine } \\
(\mathbf{g})\end{array}$ & Solvent & $\begin{array}{c}\text { Volume of solvent } \\
(\mathbf{m L})\end{array}$ & $\begin{array}{c}\text { Yield } \\
(\mathrm{g})\end{array}$ & $\begin{array}{c}\text { Yield } \\
(\mathbf{\%})\end{array}$ \\
\hline 50 & 62 & $\begin{array}{c}\text { Isopropanol }+ \\
\text { methanol }\end{array}$ & $180+60$ & 55.2 & 80.7 \\
\hline 50 & 62 & $\begin{array}{c}\text { Isopropanol }+ \\
\text { Methanol }\end{array}$ & $180+60$ & 49 & 71.7 \\
\hline 50 & 62 & $\begin{array}{c}\text { Isopropanol }+ \\
\text { Methanol }\end{array}$ & $180+60$ & 51 & 74.5 \\
\hline
\end{tabular}

\section{Conclusions}

We have demonstrated an improved one-pot synthesis of 2 and its hydrochloride salt, a useful intermediate for the preparation of 1 . The operations are simple and involve the use of simple and nonhazardous chemicals throughout the process.

\section{Acknowledgements}

The authors wish to thank the management of Dr. Reddy's Laboratories Limited for providing facilities to carry out this work and cooperation extended by all the colleagues, is gratefully acknowledged.

\section{References and Notes}

1. (a) J. Koo, S. Avakian and G. Martin, J. Am. Chem. Soc. 77, 5373 (1955). (b) M. Desai, J.W.H. Watthey and M. Zuckerman, Org. Pre. Proced. Int. 8, 85 (1976). (c) G. Butora, L. Blaha, M. Rajsner and I. Helfert, Collect. Czech. Chem. Commun. 57, 1967 (1992). (d) D. Boschi, A.D. Stilo, R. Fruttero, C. Medana and A. Gasco, Arch. Pharam. (Weinheim Ger.) 327, 661 (1994). (e) F. Novelli and F. Sparatore, Faramco. 51, 551 (1996).

2. (a) T.H. Althuis and H.J. Hess, J. Med.Chem. 20, 146 (1977). (b) P.M. Manoury, J.L. Binet, A.P. Dumas, F. Lefevre-Borg and I. Cavero, J. Med.Chem. 29, 19 (1986). (c) E. Hokanen, A. Pippuri, P. Kairisalvo, H. Thaler, M. Kolvisto and S. Taomi, J. Heterocycl.Chem. 17, 797 (1980). (d) H.J. Hess, U.S. Pat. 3,511,836 (1970) (e) M. Winn and J. Kyncl, U.S. Pat. 4,093,726 (1978). (f) R.A. Partyka and R.R. Crenshaw, U.S. Pat. 4,001237 and 4,001,238 (1977). (g) P.M. Manori, U.S. Pat. 4,315,007 (1982). (h) R. Rotman, U.S. Pat. 4,251,532 (1981). (i) T. Igarashi, Eur. Pat. 0,209,089, 1986. (j) L.H. Schlager, Eur. Pat. 0,225,886 (1986). (k) J. Konig, Ger. Pat. 3,419,223 (1984).

3. (a) S.F. Campbell, M.J. Davey, J.D. Hardstone, B.N. Lewis and M.J. Palmer, J. Med. Chem. 30, 49 (1987).

(b) F.C. Simon U.S. Pat. 4,188,390 (1980).

4. C. C. Wen, T.W. Chang, C.F. Shyh and K. Hao, J. Org. Chem. 63, 10015 (1998).

5. G. Kumaraswamy, A.K. Das and J. Nivedita. Org. Prep. Proc. Int. 35, 603 (2003).

6. K.S. Murthy, G. Weeratunga, T. Zhou, and B.R. Guntoori, U.S. Pat. 5,919,931 (1999).

7. (a) B.P. Bandgar and S.S Pandit, Tetrahedron Lett. 44, 3855 (2003). (b) C.C. Wen, C.C. Ming, Y.L. Yann and F.C. Shyh, Tetrahedron Lett. 40, 3419 (1999).

Received on March 5, 2006 